\title{
Waste-based biosorbents as cost-effective alternatives to commercial adsorbents for the retention of fluoxetine from water
}

\author{
Bruna Silva $^{\mathrm{a}, *}$, Mariana Martins ${ }^{\mathrm{a}}$, Mihaela Rosca ${ }^{\mathrm{b}}$, Verónica Rocha ${ }^{\mathrm{a}}$, Ana Lago ${ }^{\mathrm{a}}$, Isabel C. Neves ${ }^{\mathrm{c}}$, \\ Teresa Tavares ${ }^{\mathrm{a}}$ \\ ${ }^{a}$ Centre of Biological Engineering, University of Minho, Campus de Gualtar, 4710-057 Braga, Portugal \\ ${ }^{\mathrm{b}}$ Chemistry Department, University of Minho, Campus de Gualtar, 4710-057 Braga, Portugal \\ ${ }^{c}$ Department of Environmental Engineering and Management, Faculty of Chemical Engineering and Environmental Protection, Gheorghe Asachi Technical University of Iasi, \\ 73 Prof. Dr. Docent D. Mangeron Str., Iasi, Romania
}

\section{A R T I C L E I N F O}

\section{Keywords:}

Waste-based biosorbents

Activated carbon

Zeolites

Pharmaceuticals

Cost analysis

Waste valorization

\begin{abstract}
A B S T R A C T
The goal of this study is to demonstrate that waste-based biosorbents can be cost-effective and green alternatives to commercial adsorbents for the retention of pharmaceuticals. Adsorption kinetics and equilibrium measurements allowed the determination of the adsorption capacity of commercial adsorbents (GAC - granular activated carbon and two synthetic zeolites) and waste-based biosorbents (SCG - spent coffee grounds, pine bark and cork waste) for the retention of fluoxetine from water. For commercial adsorbents, the maximum adsorption capacities followed the order GAC $(233.5 \mathrm{mg} / \mathrm{g})>$ zeolite $13 \times(32.11 \mathrm{mg} / \mathrm{g})>$ zeolite $4 \mathrm{~A}(21.86 \mathrm{mg} / \mathrm{g})$, while for low-cost biosorbents, the sequence was SCG $(14.31 \mathrm{mg} / \mathrm{g})>$ pine bark $(6.53 \mathrm{mg} / \mathrm{g})>$ cork waste $(4.74 \mathrm{mg} / \mathrm{g})$. The economic feasibility of the adsorbents/biosorbents was examined through a detailed cost analysis. Commercial adsorbents present higher costs per gram of fluoxetine removed $(6.85 € / \mathrm{g}, 3.13 € / \mathrm{g}$ and $1.07 € / \mathrm{g}$ zeolite $4 \mathrm{~A}$, zeolite $13 \times$ and GAC, respectively) when compared to low-cost biosorbents $(0.92 € / \mathrm{g}, 0.41 € / \mathrm{g}$ and $0.16 € / g$ for pine bark, cork waste and SCG, respectively). It was found that SCG is the most economically viable option for fluoxetine removal, while cork waste, the second less expensive, is the most environmentally friendly biosorbent since its preparation does not generate any solid or liquid wastes. This manuscript demonstrates that the conversion of waste materials into adsorbents has a double environmental benefit for both improving waste management and protecting the environment.
\end{abstract}

\section{Introduction}

The importance of wastewater treatment as a part of a circular economy has been rising in the last years in response to the conventional "take-make-dispose" linear model. Nowadays most wastewater treatment plants are still designed for the removal of carbon, nitrogen and phosphorus compounds [1]. Although conventional wastewater treatment plants, WWTP, are effective in terms of organic matter and nutrients removal, they are not prepared for the treatment of complex micropollutants, such as pharmaceuticals [1]. Hence, several pharmaceuticals and their metabolites have been introduced in aquatic ecosystems, mainly from effluents of WWTP [2,3]. Even though pharmaceutical compounds have been detected at trace concentrations (from $\mathrm{ng} / \mathrm{L}$ to $\mu \mathrm{g} / \mathrm{L}$ levels), extremely high concentrations (up to $\mathrm{mg} / \mathrm{L}$ levels) of various pharmaceutical residues have been found in effluents from drug manufacturing facilities $[4,5]$. The release of these pollutants in the aquatic environment can lead to chronic toxicity, with effects on reproduction, and to the creation of antibiotic-resistant strains of microorganisms [6]. According to the Directive 2013/39 EU [7], there is an urgent need to evaluate new ways of reducing their input into the environment. The removal of pharmaceuticals by adsorption is one of most attractive techniques for the treatment of wastewater due to its versatility, low energy consumption, simplicity and high efficiency in the removal of pollutants [8-10]. Recent studies have demonstrated the effectiveness of using activated carbon, carbon nanotubes and synthetic zeolites in the adsorption of several pharmaceuticals belonging to different therapeutic classes [11-14]. Although these commercial adsorbents provide high removal rates, their high cost is a drawback to their application in large scale systems. Thus, the search for alternative low-cost and biodegradable adsorbents is an urgent need. In recent years, the use of wastes derived from agriculture or forestry has attracted the attention of the scientific community due to their abundance

\footnotetext{
* Corresponding author.

E-mail address: bsilva@deb.uminho.pt (B. Silva).
} 
in nature, low price, good mechanical and chemical resistance and biodegradability $[15,16]$. The use of waste materials as adsorbents is in line with a concept of a circular economy and with an increasingly stringent environmental regulation that discourages disposal practices such as landfilling and incineration [17].

Tree barks are a relatively abundant and important waste that is generated by the exploitation of wood by mankind. Amongst barks of different wood species, pine bark has particular chemical properties that have encouraged several authors to access its efficiency on the sorption of heavy metals $[18,19]$ and organic pollutants $[20,21]$ in wastewater treatment processes. Being a forestry waste, pine bark can be easily obtained and since it is a biodegradable and abundant waste its use assures an environmental-friendly and low-cost process. Likewise, cork waste has been used as a natural biosorbent for the removal of a wide range of pollutants. The use of cork waste derived from used stoppers is very attractive because its reusage decreases the costs of waste disposal, thereby contributing to environment protection. For example, Portugal has about $34 \%$ of the total production area (cork forests) and produces an average of 40 million cork stoppers per day [22]. Another agro-based waste that has been used as low-cost biosorbent in water treatment is spent coffee grounds (SCG), the solid residues obtained from the preparation of coffee using hot water. It is estimated that in average, 1 ton of green coffee beans generates $650 \mathrm{~kg}$ of spent coffee residues [23]. The European Union is by far the biggest importer and consumer of coffee, where most of the SCG is currently being incinerated or disposed of in landfills [23]. Considering the substantial amount of coffee residues produced worldwide, as well as the impacts associated to its production, its reutilization is a relevant matter.

There are very few studies in literature presenting the cost comparison between commercial adsorbents, namely activated carbon, and various alternative adsorbents, such as biomaterials derived from waste. This aspect needs further exploitation in order to encourage the large-scale use of these biosorbents. There are several benefits arising from the widespread use of waste-based adsorbents in wastewater treatment applications due to their local availability, cost effectiveness, technical feasibility and applicability [24]. Economic feasibility analysis is, probably, the most important criteria for the selection of any adsorbent material, but there is a scarcity of consistent cost analyses in literature regarding the use of non-conventional and low-cost biosorbents. The goal of this study is to measure and compare the sorption capacity of commercial adsorbents (one activated carbon and two synthetic zeolites) and low-cost biosorbents (spent coffee grounds, pine bark and cork waste) for the retention of pharmaceuticals from water. According to the OECD Health Statistics [25], Portugal reported the third highest level of consumption of antidepressants in 2015, almost twice the OECD average. Taking into consideration the consumption and occurrence of antidepressants in effluents of WWTP and in surface water of Portugal [2,26-28], fluoxetine was selected as the model molecule to be studied in this work.

The economic feasibility of low-cost biosorbents over commercial adsorbents is also examined in the present study through a detailed cost analysis.

\section{Materials and methods}

\subsection{Chemicals}

Fluoxetine-HCl ( $>$ 98\%) was purchased from Sigma-Aldrich. Table S1 (supplementary information) summarizes the major physicochemical properties of fluoxetine hydrochloride. For the determination of $\mathrm{pH}$ of zero point of charge, pHzpc, $1.0 \mathrm{M} \mathrm{H}_{2} \mathrm{SO}_{4}$ (95\%, Fisher Chemical), $1.0 \mathrm{M} \mathrm{NaOH}$ ( $\geq 97 \%$ Fisher Chemical) and $0.01 \mathrm{M} \mathrm{NaCl}$ (99.5\%, Panreac) solutions were prepared. HPLC-grade acetonitrile (Fisher Chemical), phosphoric acid (85\%, Merck) and ultra-pure water, obtained from a Milli-Q Millipore system, were used to prepare the mobile phase for fluoxetine quantification by ultra-high performance liquid chromatography (UHPLC).

\subsection{Commercial adsorbents and waste-based biosorbents}

Three commercial adsorbents were used in this study: one granular activated carbon (granules of $2.5 \mathrm{~mm}$, Merck, ref. 1.02518.1000) and two synthetic zeolites, zeolite $13 \times(3.2 \mathrm{~mm}$ pellets, Sigma-Aldrich, ref. 334359) and zeolite 4A (1.6 mm pellets, BDH Laboratory, ref. $4990580 \mathrm{H})$. The pelletized zeolites and GAC were ground with a mortar and pestle and sieved $(<1 \mathrm{~mm})$. Powdered adsorbents were dried at $105^{\circ} \mathrm{C}$ for $12 \mathrm{~h}$ and stored in a desiccator.

SCG was collected at a local coffee shop, dried and sieved through a $1 \mathrm{~mm}$ mesh in order to uniform particle size. The soluble materials of SCG were removed in contact with a $0.1 \mathrm{M} \mathrm{NaOH}$ solution for $3 \mathrm{~h}$ in an orbital incubator operating at $40{ }^{\circ} \mathrm{C}$ and $100 \mathrm{rpm}$. After that, the SCG was washed with deionized water and harvested by centrifugation, at $8000 \mathrm{rpm}$. Finally SCG was dried during $24 \mathrm{~h}$ at $70^{\circ} \mathrm{C}$, cooled to room temperature and stored in a desiccator.

Cork waste was obtained from used wine stoppers that were collected from local restaurants. Firstly, the stoppers were cut in small pieces and then milled and sieved $(<1 \mathrm{~mm})$. Finally, cork waste was dried at $50{ }^{\circ} \mathrm{C}$ during $3 \mathrm{~h}$, cooled to room temperature and stored in a desiccator.

Pine bark collected from a pine forest located in Braga (Portugal), was first washed several times with deionized water to remove dirt and mud and then dried in an oven at $60^{\circ} \mathrm{C}$, during $48 \mathrm{~h}$. Then, it was ground into a smaller particle, sieved $(<1 \mathrm{~mm})$ and washed in $0.1 \mathrm{M}$ $\mathrm{NaOH}$ solution to remove lignin materials. A second washing step was then performed with a $0.1 \mathrm{M} \mathrm{H}_{2} \mathrm{SO}_{4}$ solution. Afterwards, pine bark was washed with deionized water several times and dried in an oven at $30^{\circ} \mathrm{C}$ for 3 days. The dried pine bark was finally cooled and stored in a desiccator.

\subsection{Adsorbent characterization}

The pHzpc of the adsorbents was measured by preparing a solution of $0.01 \mathrm{M} \mathrm{NaCl}$, previously bubbled with nitrogen in order to stabilize the $\mathrm{pH}$ by preventing the dissolution of $\mathrm{CO}_{2}$. The solution $\mathrm{pH}$ was adjusted to different values between 1 and 9 by adding $1.0 \mathrm{M} \mathrm{H}_{2} \mathrm{SO}_{4}$ or $1.0 \mathrm{M} \mathrm{NaOH}$. For each $\mathrm{pH}$ value, the adsorbent $(0.10 \mathrm{~g})$ was added to $25 \mathrm{~mL}$ of $\mathrm{NaCl}$ solution in Erlenmeyer flasks that were kept under moderate agitation in an incubator at $25^{\circ} \mathrm{C}$, for $48 \mathrm{~h}$. The samples were then filtered and the final $\mathrm{pH}$ of filtrate was measured and plotted against initial $\mathrm{pH}$. The $\mathrm{pH}$ at which the curve crosses the line $\mathrm{pH}_{\text {initial }}=\mathrm{pH}_{\text {final }}$ was taken as the point of zero charge (pHpzc).

The textural characterization of the adsorbents was based on the adsorption of $\mathrm{N}_{2}$ at $77 \mathrm{~K}$ using a Micromeritics ASAP 2010 apparatus. All the samples were powdered and degassed under nitrogen flow prior to the measurement. These analyses were performed at the Faculty of Science and Technology, New University of Lisbon.

\subsection{Quantification of fluoxetine-HCl by UHPLC-DAD}

The quantification of fluoxetine was performed by UHPLC with diode array detection (UHPLC-DAD), using a Shimadzu Nexera X2 equipped with a kinetex C18 column in a gradient mode, using $0.1 \%$ phosphoric acid in ultrapure water as eluent $A$ and acetonitrile as eluent $\mathrm{B}$, at a flow rate of $0.5 \mathrm{~mL} / \mathrm{min}$. The gradient elution started with $10 \%$ of eluent B, increasing to $100 \% \mathrm{~B}$ in $5.5 \mathrm{~min}$, decreasing to $10 \% \mathrm{~B}$ in $1.0 \mathrm{~min}$ and then, maintained the initial conditions during $2.5 \mathrm{~min}$. The autosampler was operated at $4{ }^{\circ} \mathrm{C}$, an injection volume of $5 \mu \mathrm{L}$ was used and column temperature was kept at $50{ }^{\circ} \mathrm{C}$.

Method validation was performed for UHPLC analysis. The linearity of the method was established by setting a calibration curve using linear regression analysis over the concentration range $1.0-10.0 \mathrm{mg} / \mathrm{L}$. 
Method detection limit $(0.3 \mathrm{mg} / \mathrm{L})$ and method quantification limit $(0.5 \mathrm{mg} / \mathrm{L})$ were determined as the minimum amount detectable of analyte with a signal-to-noise ratio of 3 and 10, respectively. The standard solutions of fluoxetine-HCl were prepared by dilution with distilled water of a $200 \mathrm{mg} / \mathrm{L}$ stock solution (previously prepared in methanol). Two replicates of each standard were obtained and the average peak areas were used for quantification.

Lab Solutions software (version 5.71, Shimadzu Corporation) was used for system control and data processing.

\subsection{Batch adsorption experiments}

Kinetics and equilibria experiments were performed to characterize the adsorption of fluoxetine- $\mathrm{HCl}$ onto commercial adsorbents and lowcost biosorbents. In amber Erlenmeyer flasks, a pre-established mass of each material was placed in contact with $50 \mathrm{~mL}$ of fluoxetine- $\mathrm{HCl}$ solution, $5 \mathrm{mg} / \mathrm{L}$. The experiments were performed in duplicate and carried out in an orbital incubator at $25^{\circ} \mathrm{C}$ and $170 \mathrm{rpm}$.

\subsubsection{Kinetics experiments}

Kinetics measurements were performed in forehand in order to determine the equilibrium adsorption time. The suitable ratio between mass of adsorbent and volume of solution to be used in kinetics assays was previously selected based on mass ratio tests. Different amounts of each adsorbent were placed in contact with $50 \mathrm{~mL}$ of fluoxetine- $\mathrm{HCl}$ solution $5 \mathrm{mg} / \mathrm{L}$ (initially adjusted to $\mathrm{pH}$ 9), in Erlenmeyer flasks. These were shacked for $48 \mathrm{~h}$ at $25^{\circ} \mathrm{C}$, in an orbital incubator. The suspensions were then filtered through $0.22 \mu \mathrm{m}$ nylon syringe filters prior to analysis by UHPLC. The selected ratio for each material was the one corresponding to a removal of fluoxetine between $40 \%$ and $60 \%$. For the kinetic experiments, adsorbent doses of $0.1 \mathrm{~g} / \mathrm{L}$ and $1 \mathrm{~g} / \mathrm{L}$ were used for commercial adsorbents and biosorbents, respectively. The adsorbents were placed into Erlenmeyer flasks containing $50 \mathrm{~mL}$ of fluoxetine- $\mathrm{HCl}$ solution, $5 \mathrm{mg} / \mathrm{L}$. Samples were periodically taken, filtered and analyzed by UHPLC in order to determine the remaining concentration of fluoxetine in solution along time. All experiments were conducted in duplicate. The adsorption capacity at time $\mathrm{t}, q_{t}(\mathrm{mg} / \mathrm{g})$ was calculated using the following equation:

$q_{t}=\frac{\left(C_{0}-C_{t}\right) \cdot V}{m}$

where $C_{o}(\mathrm{mg} / \mathrm{L})$ is the initial concentration of fluoxetine- $\mathrm{HCl}$ solution, $C_{t}(\mathrm{mg} / \mathrm{L})$ is the concentration of fluoxetine- $\mathrm{HCl}$ in liquid phase at time $t, V(\mathrm{~L})$ is the volume of the fluoxetine- $\mathrm{HCl}$ solution and $m(\mathrm{~g})$ is the mass of the adsorbent/biosorbent. To evaluate the kinetics of the adsorption of fluoxetine, the Lagergren pseudo-first order (PFO) and the pseudo-second order (PSO) kinetic models were applied to analyse the experimental data. Origin Pro 8.0 software was used to perform the calculations.

$q_{t}=q_{e}\left[1+\exp \left(-k_{1} t\right)\right]$

$q_{t}=\frac{k_{2} \cdot q_{e}^{2} \cdot t}{1+k_{2} \cdot q_{e} \cdot t}$

$q_{\mathrm{t}}$ is the adsorption capacity at time $t(\mathrm{mg} / \mathrm{g}) ; q_{\mathrm{e}}$ is the adsorption capacity at equilibrium $(\mathrm{mg} / \mathrm{g}) ; k_{1}$ is the adsorption rate constant of pseudo-first order $\left(\mathrm{min}^{-1}\right) ; k_{2}$ is the adsorption rate constant of pseudosecond-order $\left(\mathrm{g} \mathrm{mg}^{-1} \mathrm{~min}^{-1}\right)$.

\subsubsection{Effect of solution $p H$}

The effect of the solution $\mathrm{pH}$ on the adsorption of fluoxetine by lowcost biosorbents and commercial adsorbents was investigated at $\mathrm{pH} 2$, $\mathrm{pH} 7$ and $\mathrm{pH}$ 9. The initial $\mathrm{pH}$ of fluoxetine solution was adjusted to the desire values, using $\mathrm{H}_{2} \mathrm{SO}_{4}$ and/or $\mathrm{NaOH}$ solutions. Adsorbent doses of $0.1 \mathrm{~g} / \mathrm{L}$ and $1.5 \mathrm{~g} / \mathrm{L}$ were used for commercial adsorbents and low-cost biosorbents, respectively. The adsorbents and biosorbents were placed in contact with $50 \mathrm{~mL}$ of fluoxetine solutions, $5 \mathrm{mg} / \mathrm{L}$, with initial $\mathrm{pH}$ values of 2, 7 and 9. After shacking during the equilibrium time, samples were taken, filtrated and analysed by UHPLC in order to determine the remaining concentration of fluoxetine-HCl.

\subsubsection{Adsorption equilibrium experiments}

Equilibrium experiments were performed to establish the adsorption isotherms and the maximum uptake of each sorbent. Different masses of each adsorbent/biosorbent were added to amber Erlenmeyer flasks containing $50 \mathrm{~mL}$ of $5 \mathrm{mg} / \mathrm{L}$ fluoxetine- $\mathrm{HCl}$ solution, which initial $\mathrm{pH}$ was previously adjusted to 9 . The suspensions were kept in an orbital incubator under moderate agitation, $170 \mathrm{rpm}$, at $25^{\circ} \mathrm{C}$, for the period of time needed to attain the equilibrium (previously determined in the kinetics experiments). Adsorbent doses between 0.01 and $0.1 \mathrm{~g} / \mathrm{L}$ were used for GAC while adsorbent doses in the range of 0.1-1.5 g/L were used for zeolites and low-cost biosorbents. After the equilibration time, samples were taken, filtered and analysed by UHPLC for the determination of fluoxetine- $\mathrm{HCl}$ concentration. The amount of fluoxetine adsorbed in the equilibrium, $q_{\mathrm{e}}(\mathrm{mg} / \mathrm{g})$ was calculated using Eq. (4):

$q_{e}=\frac{\left(C_{0}-C_{e}\right) \cdot V}{m}$

where $\mathrm{Ce}(\mathrm{mg} / \mathrm{L})$ is the is the equilibrium concentration of fluoxetine$\mathrm{HCl}$ in solution.

The experimental data were fitted by the Langmuir, Freundlich and Sips isotherm models (Eqs. (5), (6) and (7), respectively) in order to determine the equilibrium parameters of the systems. The models are as follows:

$q_{e}=\frac{\left(q_{\max } K_{L} C_{e}\right)}{1+K_{L} C_{e}}$

where $\mathrm{q}_{\max }$ represents the maximum adsorption capacity $(\mathrm{mg} / \mathrm{g})$ and $K_{L}$ is a constant $(\mathrm{L} / \mathrm{mg})$.

$q_{e}=K_{F} C_{e}^{1 / n}$

where $K_{\mathrm{F}}$ represents the relative adsorption capacity $\left[(\mathrm{mg} / \mathrm{g})(\mathrm{L} / \mathrm{mg})^{1 / \mathrm{n}}\right]$ and $n$ is a constant (dimensionless) related with the degree of non-linearity of the equation.

$q_{e}=\frac{q_{\max } K_{S} C_{e}^{1 / m}}{1+K_{S} C_{e}^{1 / m}}$

where $K_{\mathrm{S}}$ is the affinity constant related with the adsorption energy (L/ $\mathrm{g}$ ) and $m$ is a parameter related with the heterogeneity of the system.

\subsection{Akaike information Criterion calculation}

The Akaike Information Criterion (AIC), developed by Akaike in 1974 [29], was chosen as the methodology for model selection. This methodology attempts to find the model that best describes the data with a minimum number of free parameters. The most adequate model is the one with the lowest value of AIC. Assuming that model errors are normally and independently distributed, AIC is calculated using the following equation:

$\mathrm{AIC}=2 k+n\left[\ln \left(\frac{\mathrm{SSR}}{n-k}\right)\right]$

where $k$ is the number of parameters in the model, $n$ is the sample size and SSR is the residual sum of squares.

When the number of data points $(n)$ is small, Burnham and Anderson [30] defined a bias-adjustment or correction for the AIC, that is calculated according the Eq. (9). Since the corrected AIC ( AIC $_{c}$ ) converges to AIC as $n$ tends to infinity, Burnham and Anderson recommended that $\mathrm{AIC}_{\mathrm{c}}$ should be used instead of AIC regardless of the number of data points $(n)$. 
$\mathrm{AIC}_{\mathrm{c}}=\mathrm{AIC}+\left[\frac{2 k(k+1)}{n-k-1}\right]$

\section{Results and discussion}

\subsection{Characterization of the adsorbent materials}

The $\mathrm{pH}$ of zero point of charge (pHzpc) allows to evaluate the acid/ base character of the adsorbents, which influences the solution $\mathrm{pH}$ and the electrostatic interactions between the target molecules and the adsorbent surface.

The pHzpc corresponds to the $\mathrm{pH}$ value at which the net surface charge of the adsorbent becomes electrically neutral. At $\mathrm{pH}<\mathrm{pHzpc}$, the adsorbent surface becomes positively charged, while at $\mathrm{pH}>\mathrm{pHzpc}$, the adsorbent surface is negatively charged. The experimental results of pHzpc determination, using the $\mathrm{pH}$ drift method, are shown in Fig. S1 (supplementary information). The $\mathrm{pH}$ at which the curve crosses the line $\mathrm{pH}_{\text {initial }}=\mathrm{pHf}_{\text {inal }}$ corresponds to the pHzpc. The commercial adsorbents present pHzpc values above $\mathrm{pH} 7$, namely 8.3, 8.8 and 8.9 for GAC, zeolite $13 \times$ and zeolite 4 A, respectively. For the low-cost biosorbents, pHzpc values bellow $\mathrm{pH} 7$ were obtained, namely, 6.6 for SCG and 4.0 for pine bark and cork waste.

The data of specific surface area $\left(S_{\mathrm{BET}}\right)$, total pore volume $\left(V_{\text {total }}\right)$, micropore volume $\left(V_{\text {micro }}\right)$, mesopore volume $\left(V_{\text {meso }}\right)$ as well as the average pore size of commercial adsorbents are summarized in Table 1. It can be seen that GAC and zeolite $13 \times$ are essentially microporous solids, since micropore volume account for more than $70 \%$ of the total pore volume, while zeolite 4A is strictly mesoporous with larger pores. For commercial adsorbents, the ranking of surface area is in accordance with total pore volume as zeolite $4 \mathrm{~A}<$ zeolite $13 \times<$ GAC. For lowcost biosorbents, the results reveal negligible adsorption of $\mathrm{N}_{2}$, with surface areas below the lower limit measurable, i.e. $S_{\mathrm{BET}}<4 \mathrm{~m}^{2} / \mathrm{g}$.

\subsection{Kinetics adsorption studies}

The kinetics curves presented in Fig. 1 show that the adsorption of fluoxetine $(5 \mathrm{mg} / \mathrm{L})$ onto $\mathrm{GAC}$ takes around $30 \mathrm{~h}$ to reach equilibrium, while for zeolite $13 \times$ and $4 \mathrm{~A}$, the equilibrium was attained after $10 \mathrm{~h}$ and $20 \mathrm{~h}$, respectively. Low-cost biosorbents present faster adsorption kinetics, being the equilibrium reached between $3 \mathrm{~h}$ and $10 \mathrm{~h}$ (Fig. 2). Furthermore, both pseudo-first and pseudo-second order kinetic models fit experimental data with correlation coefficients $\left(\mathrm{R}^{2}\right)$ higher than 0.93 for all adsorbents and biosorbents tested. The choice of the best model was made according to the corrected Akaike Information Criterion $\left(\mathrm{AIC}_{\mathrm{c}}\right)$. The model with minimum $\mathrm{AIC}_{\mathrm{c}}$ value was chosen as the best one to describe experimental data. Although, statistical analysis indicate PSO model as the best one (with exception of SCG), both fittings are very similar. It is not possible to conclude about the mechanisms involved in the adsorption of fluoxetine since these mechanisms are hardly assigned based on observed kinetic experiments or by fitting kinetic models [31,32].

Considering the $k_{2}$ shown in Table 2 for the evaluated sorbents, the adsorption rate of fluoxetine follows this sequence SCG $>$ pine bark $>$ cork waste $>$ zeolite $13 \mathrm{~A}>$ zeolite $4 \mathrm{~A}>$ GAC.

Table 1

Textural characterization of commercial adsorbents.

\begin{tabular}{llllll}
\hline Adsorbent & $\begin{array}{l}S_{\mathrm{BET}} \\
\left(\mathrm{m}^{2} / \mathrm{g}\right)\end{array}$ & $\begin{array}{l}V_{\text {total }} \\
\left(\mathrm{cm}^{3} / \mathrm{g}\right)\end{array}$ & $\begin{array}{l}V_{\text {micro }} \\
\left(\mathrm{cm}^{3} / \mathrm{g}\right)\end{array}$ & $\begin{array}{l}V_{\text {meso }} \\
\left(\mathrm{cm}^{3} / \mathrm{g}\right)\end{array}$ & $\begin{array}{l}\text { Average pore } \\
\text { size }(\AA)\end{array}$ \\
\hline GAC & 1095 & 0.56 & 0.46 & 0.10 & 21 \\
Zeolite 4A & 38.4 & 0.11 & - & 0.11 & $\begin{array}{l}113 \\
20\end{array}$ \\
Zeolite 13× & 576 & 0.29 & 0.21 & 0.08 & 20 \\
\hline
\end{tabular}
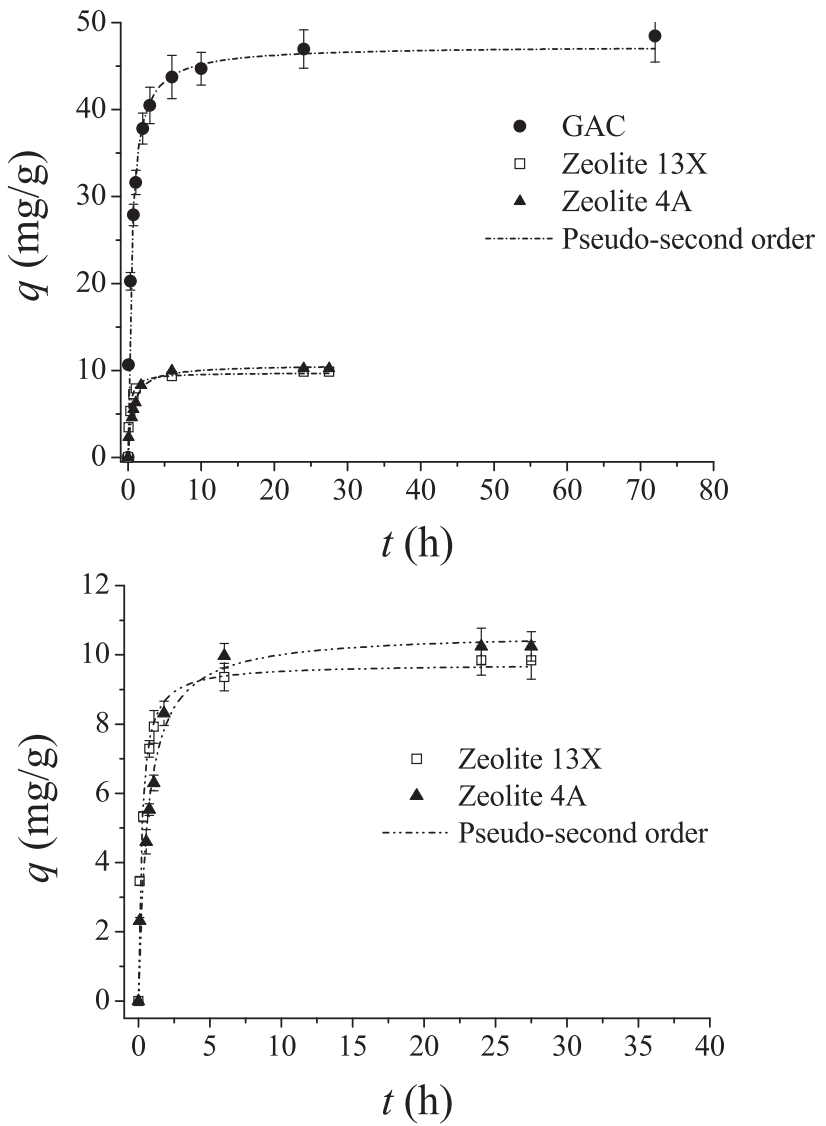

Fig. 1. Adsorption of fluoxetine along time onto GAC, zeolite $13 \times$ and zeolite 4A (a), and onto zeolite $13 \times$ and zeolite $4 \mathrm{~A}$ at a shorter $q$ scale (b). Experimental conditions: $C_{\mathrm{FXT}}=5 \mathrm{mg} / \mathrm{L}$, initial $\mathrm{pH}$ 9, adsorbent dose $0.1 \mathrm{~g} / \mathrm{L}$. The fittings presented follow the PSO kinetics model.

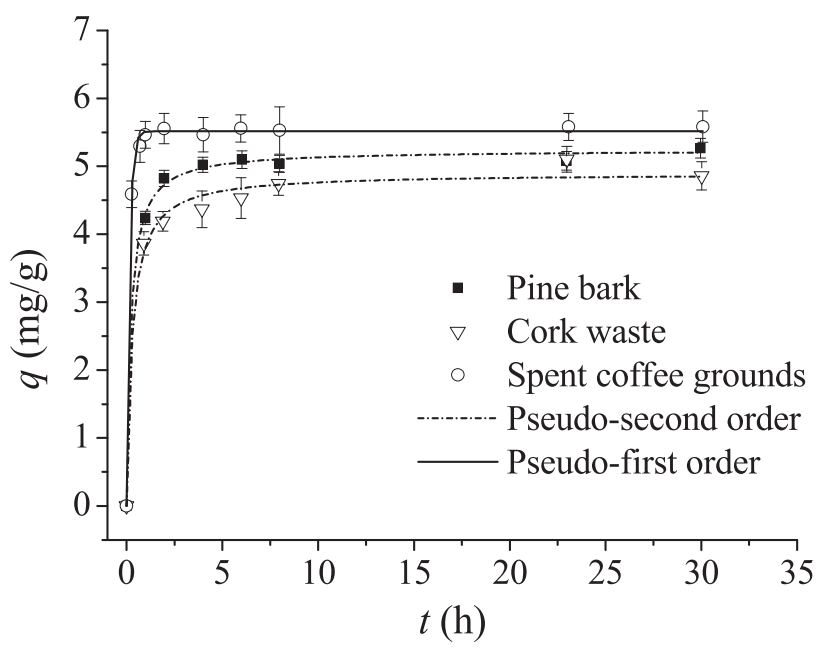

Fig. 2. Adsorption of fluoxetine onto the studied biosorbents along time and fittings by the PFO and PSO kinetic models. Experimental conditions: $C_{\text {FXT }}=5 \mathrm{mg} / \mathrm{L}$, initial $\mathrm{pH}$ 9, adsorbent dose $1 \mathrm{~g} / \mathrm{L}$.

\subsection{Effect of solution $p H$}

The effect of the solution $\mathrm{pH}$ on the adsorption of fluoxetine by commercial adsorbents and biosorbents was investigated at $\mathrm{pH} 2, \mathrm{pH} 7$ and $\mathrm{pH} 9$ (Fig. 3).

The $\mathrm{pH}$ of a solution is a very important factor in the adsorption process, considering the protonation/deprotonation of adsorbates and/ 
Table 2

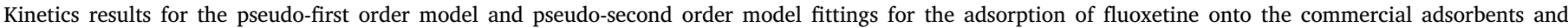
biosorbents.

\begin{tabular}{|c|c|c|c|c|c|c|c|c|}
\hline \multirow[t]{2}{*}{ Adsorbent } & \multicolumn{4}{|c|}{ Pseudo-first order } & \multicolumn{4}{|c|}{ Pseudo-second order } \\
\hline & $q_{\mathrm{e}}$ & $k_{1}$ & $\mathrm{R}^{2}$ & $\mathrm{AIC}_{\mathrm{c}}$ & $q_{\mathrm{e}}$ & $k_{2}$ & $\mathrm{R}^{2}$ & $\mathrm{AIC}_{\mathrm{c}}$ \\
\hline GAC & $44.4 \pm 1.5$ & $1.34 \pm 0.20$ & 0.953 & 32.8 & $47.3 \pm 0.8$ & $0.044 \pm 0.005$ & 0.991 & 17.8 \\
\hline Zeolite $13 \mathrm{X}$ & $9.39 \pm 0.48$ & $2.44 \pm 0.53$ & 0.937 & 4.37 & $9.74 \pm 0.26$ & $0.458 \pm 0.077$ & 0.984 & -6.47 \\
\hline Zeolite 4 A & $10.1 \pm 0.4$ & $1.03 \pm 0.12$ & 0.971 & -2.55 & $10.6 \pm 0.36$ & $0.147 \pm 0.024$ & 0.979 & -5.36 \\
\hline Pine bark & $5.09 \pm 0.04$ & $1.78 \pm 0.11$ & 0.997 & -31.5 & $5.24 \pm 0.04$ & $0.898 \pm 0.109$ & 0.998 & -34.2 \\
\hline Cork waste & $4.68 \pm 0.12$ & $1.77 \pm 0.34$ & 0.972 & -14.3 & $4.90 \pm 0.09$ & $0.727 \pm 0.154$ & 0.991 & -23.0 \\
\hline SCG & $5.51 \pm 0.03$ & $6.65 \pm 0.32$ & 0.998 & -46.1 & $5.62 \pm 0.03$ & $3.33 \pm 0.36$ & 0.998 & -45.1 \\
\hline
\end{tabular}

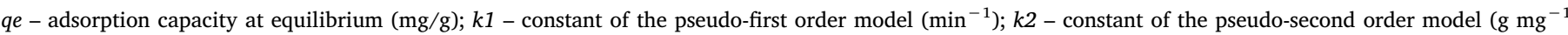
$\mathrm{min}^{-1}$ ); $\mathrm{R}^{2}$ - coefficient of correlation; $\mathrm{AIC}_{\mathrm{c}}-$ corrected Akaike Information Criterion.
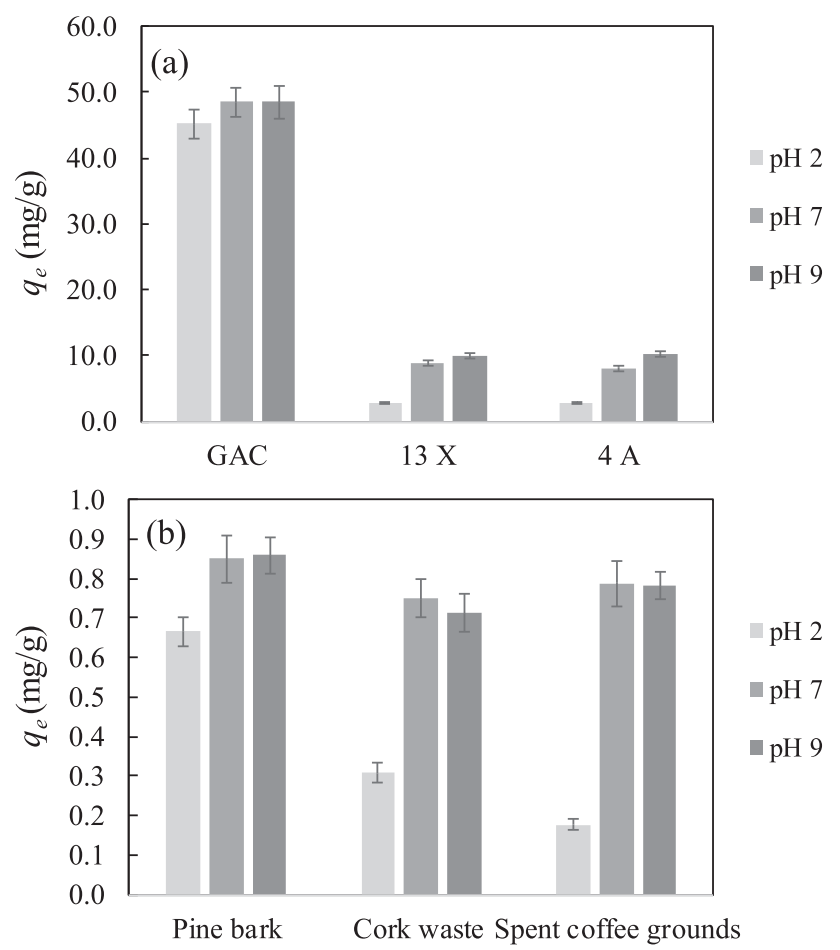

Fig. 3. Effect of solution $\mathrm{pH}$ on the uptake of fluoxetine by commercial adsorbents (a) and low-cost biosorbents (b). Experimental conditions: $C_{\mathrm{FXT}}=5 \mathrm{mg} / \mathrm{L}$, adsorbent dose $0.1 \mathrm{~g} / \mathrm{L}$ for commercial adsorbents and $1.5 \mathrm{~g} / \mathrm{L}$ for low-cost biosorbents.

or changes in the surface charges of adsorbents with different $\mathrm{pH}$ values. Comparison of the solution $\mathrm{pH}$, the $\mathrm{p} K_{\mathrm{a}}$ of the target molecule and the pHzpc of the adsorbent is useful to explain the $\mathrm{pH}$ effect.

The results presented in Figs. 4 and 5 show that the maximum uptake of fluoxetine, for all adsorbents and biosorbents, was attained at higher $\mathrm{pH}$ values, 7 and 9. The differences observed between the uptake values obtained at different $\mathrm{pH}$ values are related with the electrostatic interaction between the net surface charge of the adsorbent and the electric charge of fluoxetine molecules.

Fluoxetine speciation in solution depends on its $\mathrm{p} K_{\mathrm{a}}$ value and the actual $\mathrm{pH}$ of the medium. Fig. S2 (supplementary information) presents the species distribution of fluoxetine hydrochloride in the $\mathrm{pH}$ range from 0 to 14. The plots were obtained using the software Marvin Sketch (version 18.11). Once $\mathrm{pKa}$ of fluoxetine- $\mathrm{HCl}$ is 9.8 , at $\mathrm{pH}$ below $\mathrm{p} K_{\mathrm{a}}$ the molecule take mainly the ionized state (positive charge) and at $\mathrm{pH}$ equal to $\mathrm{p} K_{\mathrm{a}}$ the ionized and nonionized forms are both present in the same ratio, as can be seen in Fig. S2.

For all $\mathrm{pH}$ values tested $\mathrm{(pH} \mathrm{2,} \mathrm{pH} 7$ and $\mathrm{pH}$ 9) fluoxetine molecules are protonated with positive charge. $\left(\mathrm{pH}<\mathrm{p} K_{\mathrm{a}}\right)$. As determined in
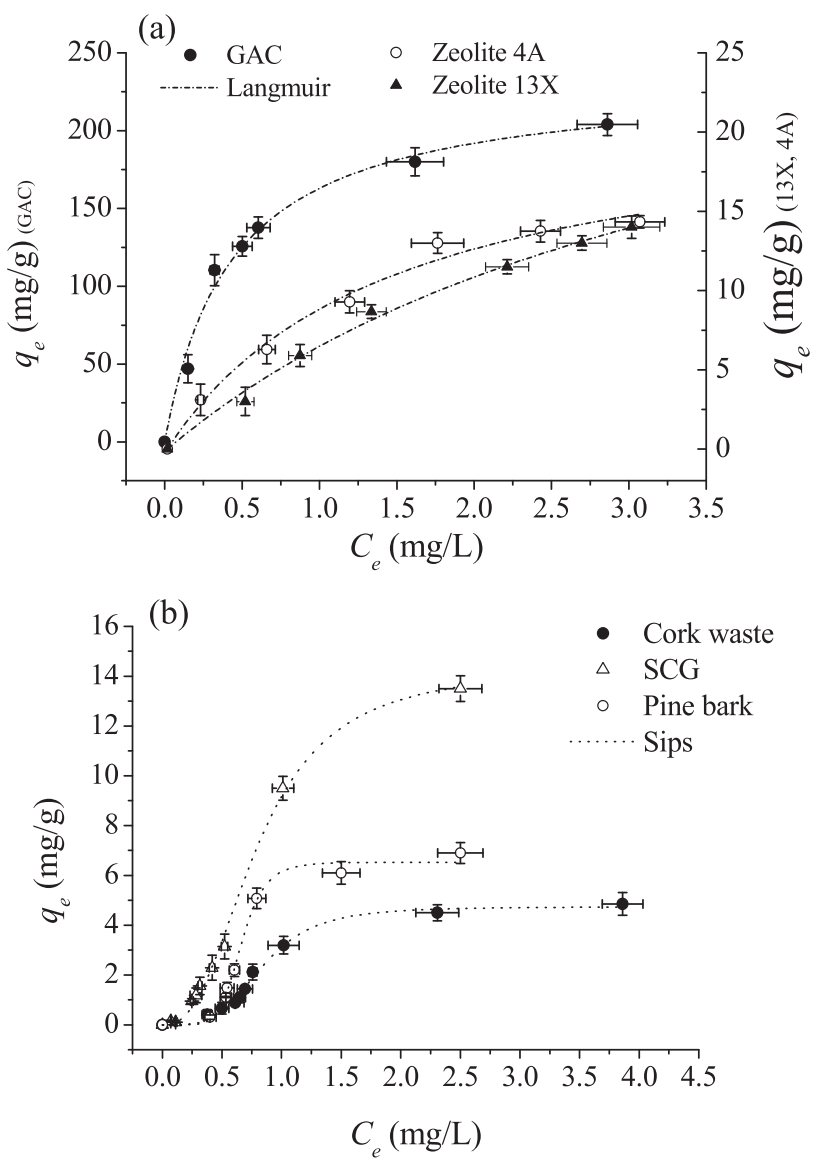

Fig. 4. Adsorption of fluoxetine onto the commercial adsorbents and low-cost biosorbents together with the fittings by the Langmuir and Sips models. Experimental conditions: $C_{\mathrm{FXT}}=5 \mathrm{mg} / \mathrm{L}$, initial $\mathrm{pH}$ 9, adsorbent dose in the range $0.01-0.1 \mathrm{~g} / \mathrm{L}$ for commercial adsorbents and in the range $0.1-1.5 \mathrm{~g} / \mathrm{L}$ for low-cost biosorbents.

section 3.1, commercial adsorbents present pHzpc values between 8.3 and 8.9, while low-cost biosorbents have pHzpc values between 4.0 and 6.6. Therefore, at $\mathrm{pH} 2$ the surface of all biosorbents and commercial adsorbents is positively charged ( $\mathrm{pH}<\mathrm{pHzpc}$ ) which lead to the electrostatic repulsion between the adsorbent and the adsorbate, explaining the lower adsorption capacity obtained at this $\mathrm{pH}$ value. At $\mathrm{pH}$ 7 and $\mathrm{pH} 9$ (above pHzpc), low-cost biosorbents are negatively charged which enhances the removal of positively charged fluoxetine molecules by electrostatic attraction. Similarly, commercial adsorbents also attained the highest adsorption capacities at $\mathrm{pH} 7$ and $\mathrm{pH} 9$. Even though the surface of these adsorbents is positively charged at pH 7 (bellow $\mathrm{pHzpc}$ ) the adsorption capacity was higher than that attained at $\mathrm{pH} 2$, 


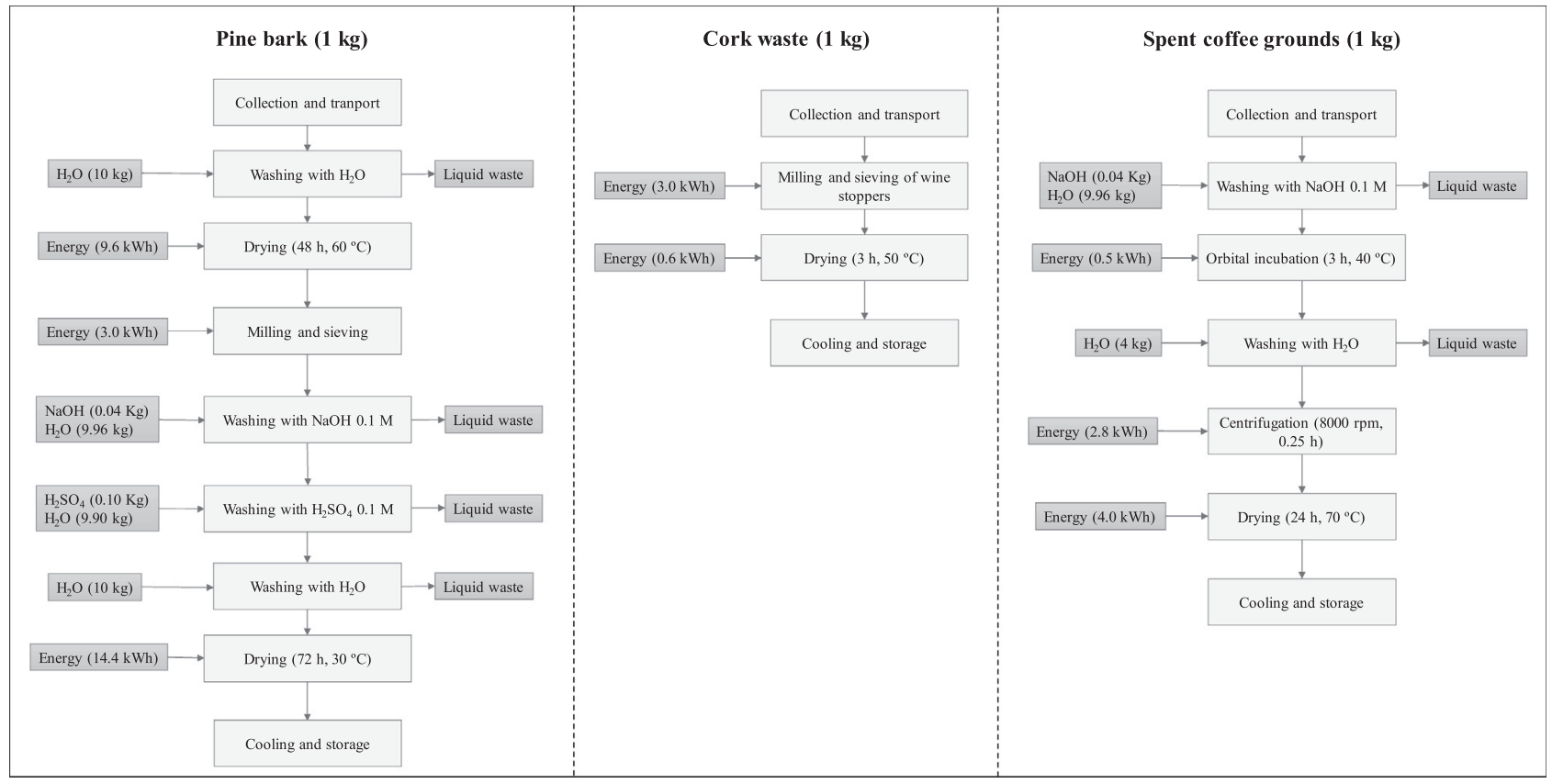

Fig. 5. Flowchart for the preparation of $1 \mathrm{~kg}$ of the studied low-cost biosorbents.

since the fraction of positively charged functional groups on the surface is smaller in comparison to that at $\mathrm{pH} 2$.

\subsection{Equilibrium adsorption studies}

Adsorption isotherms were performed in order to measure the adsorption capacity of the commercial adsorbents and low-cost biosorbents.

In this work, three common isotherm models (Langmuir, Freundlich and three-parameter Langmuir-Freundlich (Sips)) were applied to describe the equilibrium adsorption data. In order to avoid the errors which are inherent to the commonly used linearized models, nonlinear regression was used in the analyses. The results obtained from the equilibrium adsorption experiments and the fittings with isotherm models are shown in Table 3 and Fig. 4.

According to $\mathrm{AIC}_{\mathrm{c}}$ values presented in Table 3, the Langmuir model is the one that best fits the adsorption isotherms onto commercial adsorbents, while the Sips model is the one that fits more adequately the adsorption isotherms onto low-cost biosorbents. The maximum adsorption capacities, $q_{\max }$, followed the order GAC $>$ zeolite $13 \times>$ zeolite $4 \mathrm{~A}$, for commercial adsorbents, and the sequence SCG > pine bark > cork waste, for low-cost biosorbents. GAC was the adsorbent with the highest adsorption capacity, $233.5 \pm 10.4 \mathrm{mg} / \mathrm{g}$, being more than sevenfold the value determined for zeolite $13 \mathrm{X}$ and more than tenfold the value obtained for zeolite 4A. It is clear that the higher surface area and micropore volume of activated carbon in comparison with zeolites (Table 1) resulted in a higher adsorption capacity of fluoxetine. The highest value of the Langmuir affinity coefficient, $K_{\mathrm{L}}$, was attained for GAC, which points to a higher affinity of fluoxetine to this adsorbent in comparison with zeolites. Low-cost biosorbents displayed lower maximum adsorption capacities in comparison to commercial adsorbents. Amongst the biosorbents studied, SCG was the one that showed the highest saturation capacity, $14.31 \pm 0.41 \mathrm{mg} / \mathrm{g}$.

\subsection{Cost analysis}

Cost analysis is one of the most important criteria for the selection of any treatment process. The cost of adsorption processes is mainly dependent on the cost of the adsorbent used. Although activated carbon is one of the most common and efficient adsorbent used for the removal of micropollutants, its high cost is a significant disadvantage, especially for developing countries. Therefore, in the present work, an attempt is made to compare the cost of commercial and low-cost biosorbents.

Fig. 5 presents the different steps performed for obtaining $1 \mathrm{~kg}$ of each low-cost biosorbent in study (collection and transport, washing, centrifuging, drying/heating and milling/sieving steps). The cost associated with the price of the raw material, assuming the waste-based biosorbents are not available for free, was also estimated and considered for the calculation of the total cost. For each step, the input flows of energy and reagents were identified. The cost of each step and the total cost for the preparation of $1 \mathrm{~kg}$ of each biosorbent, as well as the purchase price of commercial adsorbents, are given in Table 4.

For comparison purposes, the cost for the removal of $1 \mathrm{~g}$ of

Table 3

Isotherm parameters obtained from the fitting to experimental results on the adsorption of fluoxetine onto the commercial adsorbents and biosorbents.

\begin{tabular}{|c|c|c|c|c|c|c|c|c|c|c|c|c|c|}
\hline \multirow[t]{2}{*}{ Adsorbent } & \multicolumn{4}{|l|}{ Langmuir } & \multicolumn{4}{|l|}{ Freundlich } & \multicolumn{5}{|l|}{ Sips } \\
\hline & $q_{\max }$ & $K_{\mathrm{L}}$ & $\mathrm{R}^{2}$ & $\mathrm{AIC}_{\mathrm{c}}$ & $K_{\mathrm{F}}$ & $n$ & $\mathrm{R}^{2}$ & $\mathrm{AIC}_{\mathrm{c}}$ & $q_{\max }$ & $K_{\mathrm{S}}$ & $m$ & $\mathrm{R}^{2}$ & $\mathrm{AIC}_{\mathrm{c}}$ \\
\hline GAC & $233.5 \pm 10.4$ & $2.309 \pm 0.304$ & 0.988 & 35.8 & $148.5 \pm 7.2$ & $2.89 \pm 0.44$ & 0.947 & 46.2 & $215.0 \pm 13.9$ & $3.46 \pm 1.21$ & $1.24 \pm 0.21$ & 0.989 & 42.4 \\
\hline Zeolite $13 \times$ & $32.11 \pm 3.96$ & $0.276 \pm 0.054$ & 0.994 & -6.00 & $6.77 \pm 0.32$ & $1.39 \pm 0.11$ & 0.988 & -0.93 & $19.01 \pm 2.25$ & $0.60 \pm 0.13$ & $1.43 \pm 0.18$ & 0.997 & -3.53 \\
\hline Zeolite 4 A & $21.86 \pm 1.95$ & $0.738 \pm 0.149$ & 0.988 & 0.21 & $8.81 \pm 046$ & $1.88 \pm 0.23$ & 0.973 & 5.79 & $20.64 \pm 5.00$ & $0.82 \pm 0.42$ & $1.06 \pm 0.27$ & 0.985 & 8.67 \\
\hline Pine bark & $21.30 \pm 18.74$ & $0.214 \pm 0.255$ & 0.803 & 9.39 & $3.56 \pm 0.55$ & $1.20 \pm 0.30$ & 0.783 & 10.2 & $6.53 \pm 0.19$ & $15.8 \pm 6.6$ & $6.74 \pm 0.78$ & 0.991 & -9.30 \\
\hline Cork waste & $10.24 \pm 3.35$ & $0.271 \pm 0.139$ & 0.884 & -5.03 & $2.04 \pm 0.26$ & $1.39 \pm 0.23$ & 0.849 & -2.39 & $4.74 \pm 0.13$ & $1.92 \pm 0.32$ & $3.87 \pm 0.40$ & 0.990 & -25.4 \\
\hline SCG & $48.30 \pm 30.22$ & $0.163 \pm 0.132$ & 0.931 & 9.33 & $6.28 \pm 0.64$ & $1.11 \pm 0.15$ & 0.918 & 11.1 & $14.31 \pm 0.41$ & $1.78 \pm 0.24$ & $2.54 \pm 0.15$ & 0.996 & -15.6 \\
\hline
\end{tabular}


Table 4

Comparison between purchase cost of commercial adsorbents and total cost for preparing $1 \mathrm{~kg}$ of low-cost biosorbents.

\begin{tabular}{|c|c|c|c|c|c|c|c|c|c|c|}
\hline \multirow{2}{*}{$\begin{array}{l}\text { Biosorbent/ } \\
\text { adsorbent }\end{array}$} & \multirow{2}{*}{$\begin{array}{l}\text { Purchase cost } \\
(€ / \mathrm{kg})\end{array}$} & \multirow{2}{*}{$\begin{array}{l}\text { Raw material } \\
\text { cost }(€ / \mathrm{kg})\end{array}$} & \multirow{2}{*}{$\begin{array}{l}\text { Collection and } \\
\text { transport }(€ / \mathrm{kg})\end{array}$} & \multicolumn{4}{|c|}{ Pre-treatment cost $(€ / \mathrm{kg})$} & \multirow{2}{*}{$\begin{array}{l}\text { Net cost } \\
-(€ / \mathrm{kg})\end{array}$} & \multirow{2}{*}{$\begin{array}{l}\text { Overhead costs } \\
(10 \% \text { of net cost) } \\
(€ / \mathrm{kg})\end{array}$} & \multirow{2}{*}{$\begin{array}{l}\text { Total cost } \\
(€ / \mathrm{kg})\end{array}$} \\
\hline & & & & Washing $^{\text {(a) }}$ & Centrifuging $^{(\mathrm{b})}$ & $\begin{array}{l}\text { Drying or } \\
\text { heating }^{(b)}\end{array}$ & $\begin{array}{l}\text { Milling and } \\
\text { sieving }^{(\mathrm{b})}\end{array}$ & & & \\
\hline Pine bark & - & 0.20 & 0.25 & 0.92 & - & 3.84 & 0.24 & 5.45 & 0.55 & 6.00 \\
\hline Cork waste & - & 1.20 & 0.25 & - & - & 0.10 & 0.24 & 1.79 & 0.18 & 1.97 \\
\hline SCG & - & 0.10 & 0.25 & 0.41 & 0.45 & 0.86 & - & 2.07 & 0.21 & 2.28 \\
\hline GAC & 250 & - & - & - & - & - & - & - & - & 250 \\
\hline Zeolite $13 \times$ & 100 & - & - & - & - & - & - & - & - & 100 \\
\hline Zeolite 4 A & 150 & - & - & - & - & - & - & - & - & 150 \\
\hline
\end{tabular}

(a) Considered costs for washing step: $10 € / \mathrm{kg}$ for pure $\mathrm{NaOH}, 9 € / \mathrm{L}$ for $\mathrm{H}_{2} \mathrm{SO}_{4} 95 \%$ and $0.90 € / \mathrm{m}^{3}$ for $\mathrm{H}_{2} \mathrm{O}$.

(b) It was considered the use of the following equipment: centrifuge ( $1200 \mathrm{~W}$ ) for solids separation, oven for heating and drying operations (200 W) and laboratory mill $(1500 \mathrm{~W})$. The cost of electricity was considered as $0.16 € / \mathrm{kWh}$.

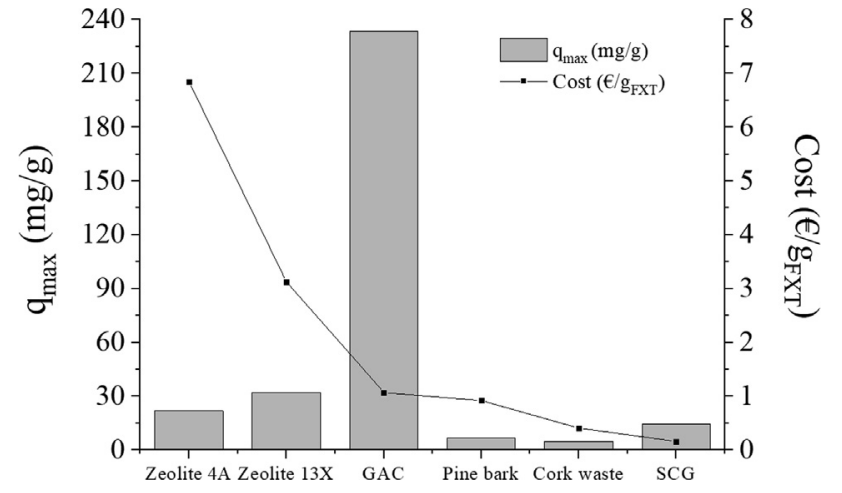

Fig. 6. Adsorption capacity of commercial and low-cost biosorbents and respective cost for the removal of $1 \mathrm{~g}$ of fluoxetine from water.

fluoxetine from water was calculated dividing the total cost of the sorbent (Table 4) by its value of $\mathrm{q}_{\max }$ (Table 3). The calculated cost $\left(€ / g_{\mathrm{FXT}}\right)$ as well as the maximum adsorption capacity for each biosorbent/adsorbent are represented in Fig. 6. As it can be observed, commercial adsorbents, GAC and zeolites, present higher costs when compared to low-cost biosorbents. Although GAC is the less expensive amongst the commercial adsorbents, with a cost of $1.07 € / \mathrm{g}_{\mathrm{FXT}}$, it is still more expensive than any of the studied biosorbents. Amongst the lowcost biosorbents, SCG presents the lowest cost per gram of fluoxetine removed, $0.16 €$, while cork waste is the second less expensive biosorbent with a cost of $0.41 € / \mathrm{g}$. Pine bark is the biosorbent that presents the highest cost per gram of fluoxetine removed, $0.92 €$, which is due to the higher number of required pre-treatment steps along its preparation.

Besides economic aspects, the selection of an adsorbent should also take in account its environmental impact. Although the cost of cork waste is almost 2.6-fold higher than SCG, this waste is still a good choice to be used as biosorbent since there are no solid or liquid wastes associated to its preparation (milling and drying operations present reduced environmental impacts). On the opposite, the preparation of pine bark involves the use of acid and alkaline aqueous solutions, resulting in the production of wastewater, which should be avoided. Therefore, economic analysis and environmental assessments should always be performed before the selection of the most suitable adsorbent/biosorbent for a real application.

\section{Conclusions}

This work presents a comprehensive and detailed comparison between commercial adsorbents and waste-based biosorbents for the removal of fluoxetine from water.

It was found that $\mathrm{pH}$ strongly influences the adsorption capacity due to the electrostatic interactions between the net surface charge of the sorbent and the electric charge of fluoxetine molecules. The maximum uptake capacities were attained at higher $\mathrm{pH}$ values, 7 and 9, since the surface of the adsorbents and biosorbents are mainly negatively charged at these $\mathrm{pH}$ values, which enhance the electrostatic interactions with the positively charge fluoxetine molecules.

Equilibrium experimental data were satisfactorily described by the Langmuir model for commercial adsorbents, while Sips model was the one that fitted better the equilibrium data for waste-based biosorbents. Waste-based biosorbents displayed lower maximum adsorption capacities $(14.31 \mathrm{mg} / \mathrm{g}, 6.53 \mathrm{mg} / \mathrm{g}$ and $4.74 \mathrm{mg} / \mathrm{g}$ for SCG, pine bark and cork waste, respectively) in comparison to commercial adsorbents (233.5 mg/g, $32.11 \mathrm{mg} / \mathrm{g}$ and $21.86 \mathrm{mg} / \mathrm{g}$ for GAC, zeolite $13 \times$ and zeolite $4 \mathrm{~A}$, respectively). The economic feasibility of low-cost biosorbents over commercial adsorbents was examined in the present study by making a detailed cost analysis. In terms of cost per gram of fluoxetine removed, commercial adsorbents present higher costs $(6.85 € / \mathrm{g}$, $3.13 € / g$ and $1.07 € / g$ for zeolite $4 \mathrm{~A}$, zeolite $13 \times$ and GAC, respectively) when compared to low-cost biosorbents $(0.92 € / g, 0.41 € / g$ and $0.16 € / g$ for pine bark, cork waste and SCG, respectively). SCG is the most economical biosorbent, while cork waste is the most environmentally friendly since its preparation present reduced environmental impacts, without the generation of solid or liquid wastes. Therefore, this study demonstrates that waste-based biosorbents may be successfully applied and be cost-effective for the removal of fluoxetine from water.

Adsorption technology employing wastes has a double environmental benefit, namely pollution mitigation and valorization of residues that otherwise would be difficult to handle and dispose. The use of alternative biosorbents capable to compete with the commercially available adsorbents is still an emerging field of research that requires further exploitation.

\section{Declaration of Competing Interest}

The authors declare that they have no competing financial interests for this paper.

\section{Acknowledgements}

This study was supported by the Portuguese Foundation for Science and Technology (FCT) under the scope of the research project PTDC/ AAG-TEC/5269/2014, the strategic funding of UID/BIO/04469/2013 unit and COMPETE 2020 (POCI-01-0145-FEDER-006684) and BioTecNorte operation (NORTE-01-0145-FEDER-000004) funded by the European Regional Development Fund under the scope of Norte2020 - Programa Operacional Regional do Norte. Bruna Silva thanks FCT for a postdoctoral grant (SFRH/BPD/112354/2015). 


\section{Appendix A. Supplementary material}

Supplementary data to this article can be found online at https:// doi.org/10.1016/j.seppur.2019.116139.

\section{References}

[1] P. Verlicchi, M. Al Aukidy, E. Zambello, Occurrence of pharmaceutical compounds in urban wastewater: removal, mass load and environmental risk after a secondary treatment-a review, Sci. Total Environ. 429 (2012) 123-155, https://doi.org/10. 1016/j.scitotenv.2012.04.028.

[2] B. Silva, F. Costa, I.C. Neves, T. Tavares, Psychiatric Pharmaceuticals as Emerging Contaminants in Wastewater, Springer International Publishing, 2015.

[3] F. Costa, A. Lago, V. Rocha, Ó. Barros, L. Costa, Z. Vipotnik, B. Silva, T. Tavares, A review on biological processes for pharmaceuticals wastes abatement - a growing threat to modern society, Environ. Sci. Technol. 53 (2019) 7185-7202, https://doi. org/10.1021/acs.est.8b06977.

[4] D.G.J. Larsson, C. de Pedro, N. Paxeus, Effluent from drug manufactures contains extremely high levels of pharmaceuticals, J. Hazard. Mater. 148 (2007) 751-755, https://doi.org/10.1016/j.jhazmat.2007.07.008.

[5] Y. Lester, H. Mamane, I. Zucker, D. Avisar, Treating wastewater from a pharmaceutical formulation facility by biological process and ozone, Water Res. 47 (2013) 4349-4356, https://doi.org/10.1016/j.watres.2013.04.059.

[6] H. Sanderson, R.A. Brain, D.J. Johnson, C.J. Wilson, K.R. Solomon, Toxicity classification and evaluation of four pharmaceuticals classes: antibiotics, antineoplastics, cardiovascular, and sex hormones, Toxicology 203 (2004) 27-40, https://doi.org/10.1016/j.tox.2004.05.015.

[7] European Parliament, Directive 2013/39/EU of the European Parliament and of the Council of 12 August 2013 amending Directives 2000/60/EC and 2008/105/EC as regards priority substances in the field of water policy. Off. J. Eur. Union L226., 2013, pp. 1-17.

[8] M.J. Ahmed, B.H. Hameed, Removal of emerging pharmaceutical contaminants by adsorption in a fixed-bed column: a review, Ecotoxicol. Environ. Saf. 149 (2018) 257-266, https://doi.org/10.1016/j.ecoenv.2017.12.012.

[9] M.J. Ahmed, Adsorption of non-steroidal anti-inflammatory drugs from aqueous solution using activated carbons: review, J. Environ. Manage. 190 (2017) 274-282, https://doi.org/10.1016/j.jenvman.2016.12.073.

[10] V. Calisto, G. Jaria, C.P. Silva, C.I.A. Ferreira, M. Otero, V.I. Esteves, Single and multi-component adsorption of psychiatric pharmaceuticals onto alternative and commercial carbons, J. Environ. Manage. 192 (2017) 15-24, https://doi.org/10. 1016/j.jenvman.2017.01.029.

[11] C. Jung, A. Son, N. Her, K.-D. Zoh, J. Cho, Y. Yoon, Removal of endocrine disrupting compounds, pharmaceuticals, and personal care products in water using carbon nanotubes: a review, J. Ind. Eng. Chem. 27 (2015) 1-11, https://doi.org/10.1016/j. jiec.2014.12.035.

[12] W.A. Cabrera-Lafaurie, F.R. Román, A.J. Hernández-Maldonado, Removal of salicylic acid and carbamazepine from aqueous solution with Y-zeolites modified with extraframework transition metal and surfactant cations: equilibrium and fixed-bed adsorption, J. Environ. Chem. Eng. 2 (2014) 899-906, https://doi.org/10.1016/j. jece.2014.02.008

[13] A. Martucci, L. Pasti, N. Marchetti, A. Cavazzini, F. Dondi, A. Alberti, Adsorption of pharmaceuticals from aqueous solutions on synthetic zeolites, Micropor. Mesopor. Mater. 148 (2012) 174-183, https://doi.org/10.1016/j.micromeso.2011.07.009.

[14] V. Rakić, N. Rajić, A. Daković, A. Auroux, The adsorption of salicylic acid, acetylsalicylic acid and atenolol from aqueous solutions onto natural zeolites and clays: clinoptilolite, bentonite and kaolin, Micropor. Mesopor. Mater. 166 (2013) 185-194, https://doi.org/10.1016/j.micromeso.2012.04.049.

[15] M.P. Dragana, Ć. Lidija, M. Jelena, Ž. Krunoslav, Eggshell as a new biosorbent for the removal of pharmaceuticals from aqueous solutions, Clean - Soil Air, Water 45 (2017) 1700082, https://doi.org/10.1002/clen.201700082.

[16] E. Rosales, J. Meijide, T. Tavares, M. Pazos, M.A. Sanromán, Grapefruit peelings as a promising biosorbent for the removal of leather dyes and hexavalent chromium, Process Saf. Environ. Prot. 101 (2016) 61-71, https://doi.org/10.1016/j.psep. 2016.03.006.

[17] European Commission, European Commission, 2016. < http://ec.europa.eu/ environment/waste/framework/ > (accessed January 28, 2019).

[18] L. Cutillas-Barreiro, L. Ansias-Manso, D. Fernández-Calviño, M. Arias-Estévez, J.C. Nóvoa-Muñoz, M.J. Fernández-Sanjurjo, E. Álvarez-Rodríguez, A. NúñezDelgado, Pine bark as bio-adsorbent for $\mathrm{Cd}, \mathrm{Cu}, \mathrm{Ni}, \mathrm{Pb}$ and $\mathrm{Zn}$ : Batch-type and stirred flow chamber experiments, J. Environ. Manage. 144 (2014) 258-264, https://doi.org/10.1016/j.jenvman.2014.06.008.

[19] R. Paradelo, L. Cutillas-Barreiro, D. Soto-Gómez, J.C. Nóvoa-Muñoz, M. AriasEstévez, M.J. Fernández-Sanjurjo, E. Álvarez-Rodríguez, A. Núñez-Delgado, Study of metal transport through pine bark for reutilization as a biosorbent, Chemosphere 149 (2016) 146-153, https://doi.org/10.1016/j.chemosphere.2016.01.087.

[20] S. Sousa, P. Jimenez-Guerrero, A. Ruiz, N. Ratola, A. Alves, Organochlorine pesticides removal from wastewater by pine bark adsorption after activated sludge treatment, Environ. Technol. 32 (2011) 673-683, https://doi.org/10.1080/ 09593330.2010.510535.

[21] E. Nehrenheim, M. Odlare, B. Allard, Retention of 2,4,6-trinitrotoluene and heavy metals from industrial waste water by using the low cost adsorbent pine bark in a batch experiment, Water Sci. Technol. 64 (2011) 2052-2058, https://doi.org/10. 2166/wst.2011.603.

[22] J. Sierra-Pérez, J. Boschmonart-Rives, X. Gabarrell, Production and trade analysis in the Iberian cork sector: economic characterization of a forest industry, Resour. Conserv. Recycl. 98 (2015) 55-66, https://doi.org/10.1016/j.resconrec.2015.02. 011.

[23] T.M. Mata, A.A. Martins, N.S. Caetano, Bio-refinery approach for spent coffee grounds valorization, Bioresour. Technol. 247 (2018) 1077-1084, https://doi.org/ 10.1016/j.biortech.2017.09.106

[24] S. Babel, T.A. Kurniawan, Low-cost adsorbents for heavy metals uptake from contaminated water: a review, J. Hazard. Mater. 97 (2003) 219-243, https://doi.org/ 10.1016/S0304-3894(02)00263-7.

[25] OECD, Pharmaceutical consumption, Health at a Glance: Europe 2017, 2017.

[26] P. Paíga, L.H.M.L.M. Santos, S. Ramos, S. Jorge, J.G. Silva, C. Delerue-Matos, Presence of pharmaceuticals in the Lis river (Portugal): sources, fate and seasonal variation, Sci. Total Environ. 573 (2016) 164-177, https://doi.org/10.1016/j. scitotenv.2016.08.089.

[27] A.M.P.T. Pereira, L.J.G. Silva, C.S.M. Laranjeiro, L.M. Meisel, C.M. Lino, A. Pena, Human pharmaceuticals in Portuguese rivers: The impact of water scarcity in the environmental risk, Sci. Total Environ. 609 (2017) 1182-1191, https://doi.org/10 1016/j.scitotenv.2017.07.200.

[28] L.J.G. Silva, A.M.P.T. Pereira, L.M. Meisel, C.M. Lino, A. Pena, A one-year follow-up analysis of antidepressants in Portuguese wastewaters: occurrence and fate, seasonal influence, and risk assessment, Sci. Total Environ. 490 (2014) 279-287, https://doi.org/10.1016/j.scitotenv.2014.04.131.

[29] H. Akaike, A new look at the statistical model identification, IEEE Trans. Automat. Contr. 19 (1974) 716-723, https://doi.org/10.1109/TAC.1974.1100705.

[30] K.P. Burnham, D.R. Anderson, Multimodel inference: understanding AIC and BIC in Model Selection, Sociol. Methods Res. 33 (2004) 261-304, https://doi.org/10. $1177 / 0049124104268644$.

[31] H.N. Tran, S.-J. You, A. Hosseini-Bandegharaei, H.-P. Chao, Mistakes and inconsistencies regarding adsorption of contaminants from aqueous solutions: a critical review, Water Res. 120 (2017) 88-116, https://doi.org/10.1016/j.watres.2017.04. 014.

[32] É.C. Lima, M.A. Adebayo, F.M. Machado, Kinetic and equilibrium models of adsorption, Carbon Nanostruct. (2015) 33-69, https://doi.org/10.1007/978-3-31918875-1_3. 